\title{
TOPOLOGY DESIGN AND MODAL ANALYSIS OF A BRACKET VIA FEA
}

\author{
Original scientific paper
}

UDC: $629.7 .02: 519.6$

https://doi.org/10.18485/aeletters.2019.4.3.5

\begin{abstract}
Erdi Gülbahçe ${ }^{1 *}$, Haşmet Çağrı Sezgen ${ }^{2}$ and Abdullah Çakan ${ }^{3}$
${ }^{1}$ KTO Karatay University, Faculty of Engineering, Mechatronics Engineering Department, Konya, Turkey

${ }^{2}$ KTO Karatay University, Vocational School of Trade and Industry, Mechatronics Program, Konya, Turkey

${ }^{3}$ Konya Technical University, Faculty of Engineering and Natural Sciences, Mechanical Engineering

Department, Konya, Turkey
\end{abstract}

\begin{abstract}
:
In this study, topology optimization of a jet engine bracket which was proposed from GE Aviation challenge for improving the brackets is presented using finite element analysis (FEA). The minimum mass, maximum equivalent stress and first natural frequency are selected for the objective functions to topology optimization. Then, topology optimization procedure is implemented according to the identified boundary conditions and objective functions. Finally, the manufacturing model is obtained and compared with the original model according to the maximum equivalent stress, mass reduction and first natural frequency. Also, modal analysis and static analysis results of the proposed models are presented.
\end{abstract}

ARTICLE HISTORY

Received: 20.09.2019.

Accepted: 27.09.2019.

Available: 30.09.2019.

\section{KEYWORDS}

Topology design, optimization, bracket design, FEA, ANSYS

\section{INTRODUCTION}

In the industry, it is desirable that most structures do not change their strength when their weights and dimensions decrease. Similarly, structural strength and durability are important properties in vibration problems. In the structures subjected to the vibrations, the brackets are more affected and damaged than the main structures. There are many commercial and academic studies about bracket design. The researchers used the topology optimization method for bracket design and achieved good results [1-3]. In another aspect, the researchers investigate the vibration characteristics of brackets in order to optimize of the bracket design [4, 5]. In another study, topology optimization is conducted in order to analyze the compressor bracket by several loading condition [6]. In this study, the constraint is selected the first natural frequency for objective function. From the results, topology optimization method shows good performance to right design direction at the early development stage. The brackets are subject to mechanical dynamic loads and stresses depending on the environment. As presented in [7], an FSAE car is a high performance vehicle. Thus, the static and dynamic stresses as well as huge amount of vibrations are occurred in the brackets as the engine supports. For this aim, the mass optimization of engine mount brackets for a FSAE car is carried out by using finite Element Analysis and Modal analysis [7]. In other study, three different optimization procedures which are topology, shape, and size are presented. As a result of the study, it is showed that how these optimization methods are effect to mechanical properties of the bracket [8].

\section{MATERIAL AND METHODS}

\subsection{Numerical Modeling of the Jet Engine Bracket}

In this section, a jet engine bracket proposed from the GE Aviation [9] is numerically modeled using ANSYS which is the finite element software. The mesh model of the original structure is shown in Fig.1a. The mesh size is chosen as $4 \mathrm{~mm}$ and the element number is 10290. Also, boundary 
conditions of the numerical model are shown as Fig.1b. Here, a load of $7000 \mathrm{~N}$ is applied to the red regions for the static analysis and the frictionless support is applied to the structure from the blue regions. A frictionless support is also applied between the bottom face of the bracket and the ground. In this study, these boundary conditions are used for all models in the all presented analyzes.

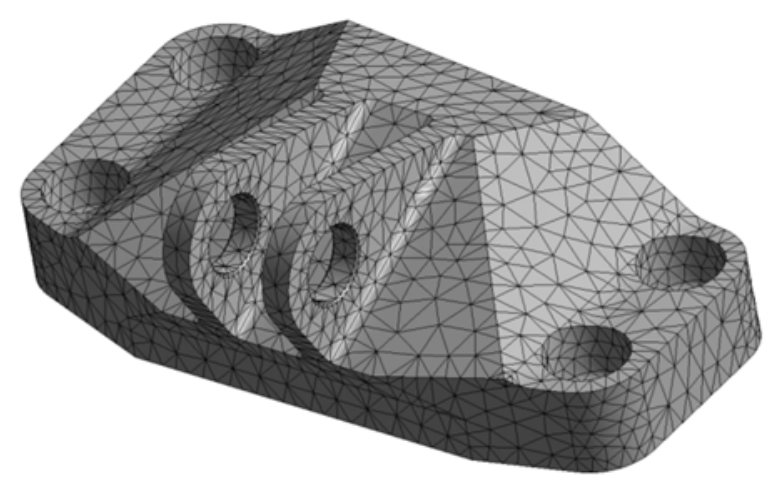

a)

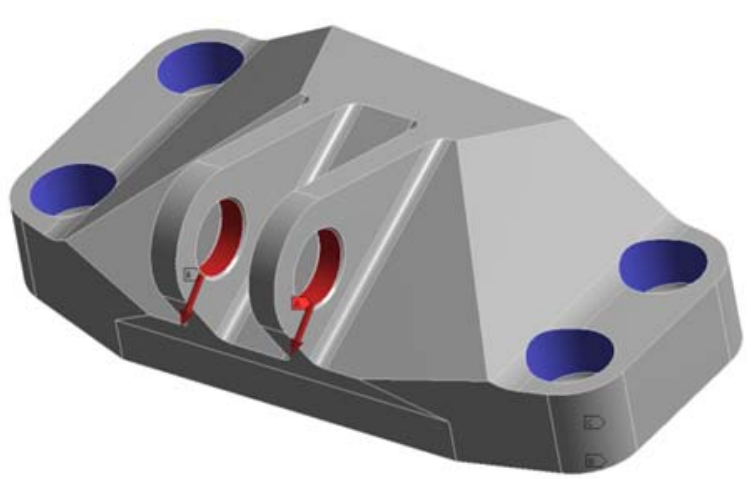

b)

Fig.1. a) Mesh model of the numerical model, b) Boundary conditions of the numerical model

Titanium alloys are generally used in avionic systems due to their lightness and durability [10]. In the numerical modeling, Ti6Al4V material is selected and mechanical properties are shown in Table 1. This material is preferred because of its high strength and light weight.

Table 1. Mechanical properties of the used material

\begin{tabular}{|l|l|}
\hline Ti6AlV & \\
\hline Density & $4430 \mathrm{~kg} / \mathrm{m}^{3}$ \\
\hline Young's Modulus & $113,8 \mathrm{GPa}$ \\
\hline Poisson's Ratio & 0,342 \\
\hline Bulk Modulus & $120 \mathrm{GPa}$ \\
\hline Shear Modulus & $42,4 \mathrm{GPa}$ \\
\hline Tensile Yield Strength & $880 \mathrm{MPa}$ \\
\hline Compressive Yield Strength & $970 \mathrm{MPa}$ \\
\hline Tensile Ultimate Strength & $950 \mathrm{MPa}$ \\
\hline
\end{tabular}

\subsection{Topology Optimization of the Jet Engine Bracket}

Topology optimization is effective method for the mechanical design for the engineering especially at the concept design stage [11]. In this section, topology optimization is implemented to the original numerical model in order to mass reduction as main objective. For this aim, topology optimization toolbox is used in ANSYS software. Totally, there are three objective functions are used in order to provide optimum geometry design. These are the mass reduction, maximum equivalent stress and first natural frequency, respectively. The first one is the mass reduction that the rate of $80 \%$. The second one is minimizing maximum equivalent stress according to the level of the original model result. The last one is the first natural frequency which is bounded at the defined value.

In the picture Fig.2a is shown optimized model, and Fig.2b manufacturing model.
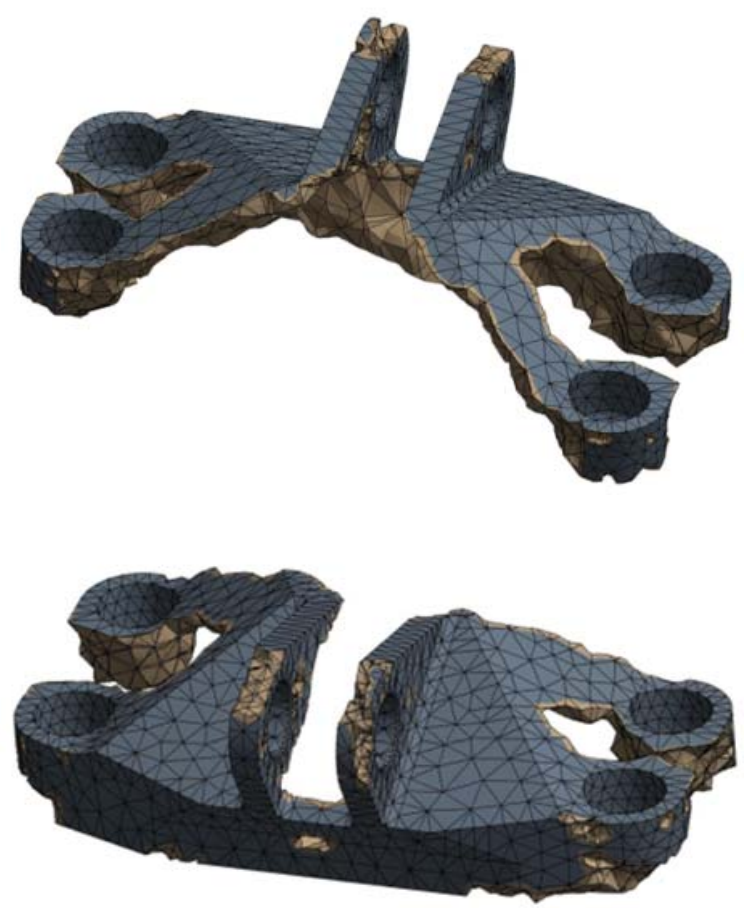

a)

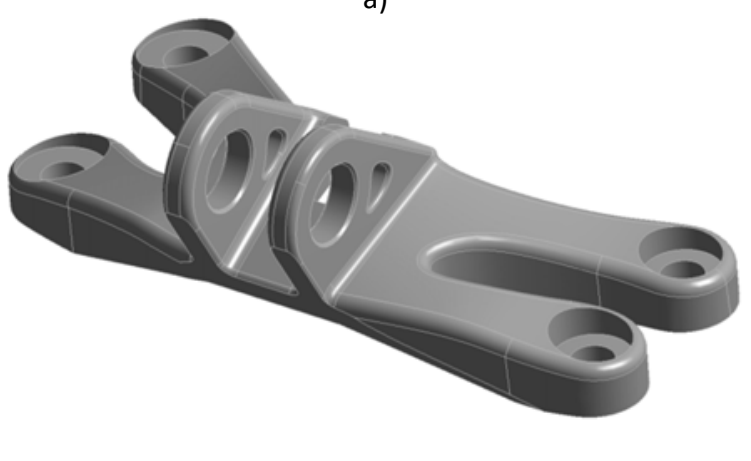




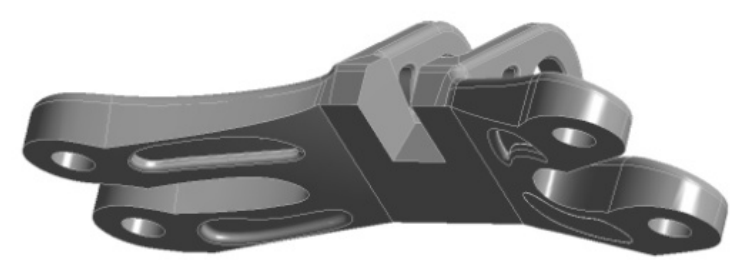

b)

Fig.2. a) Optimized model, (b) Manufacturing model

\section{RESULTS AND DISCUSSION}

After the topology optimization, the manufacturing model and original model compared according to the maximum equivalent stress. Under the applied loads, $128.21 \mathrm{MPa}$ and $135.55 \mathrm{MPa}$ maximum equivalent stress value is obtained from the original model and manufacturing model, respectively. The equivalent stresses of the proposed models are shown in Fig.3.

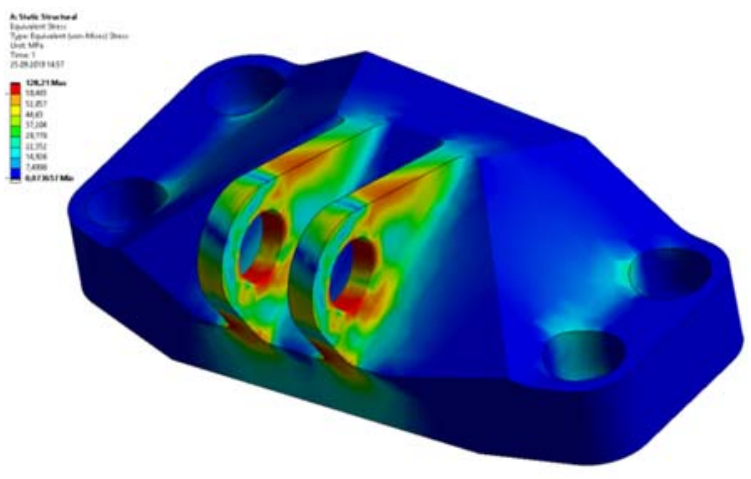

a)

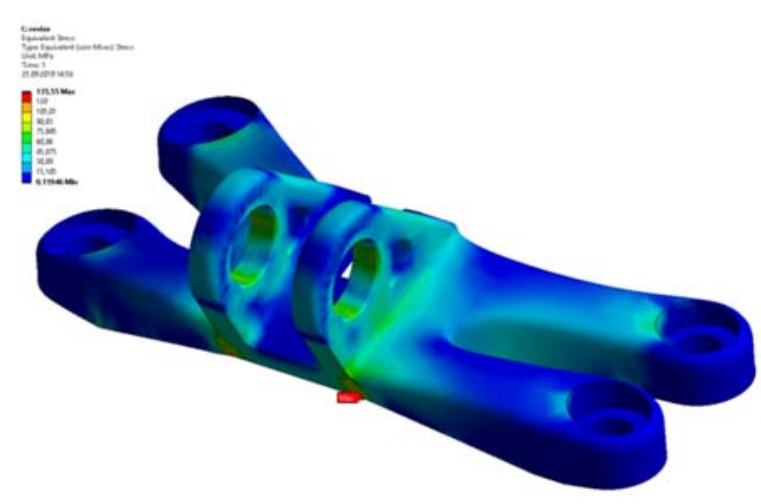

b)

Fig.3. Stress results of the (a) original model, (b) manufacturing model

Also, the manufacturing model and original model compared according to the modal analysis results. The mode shape of the first natural frequency of the proposed models is shown Fig.4.

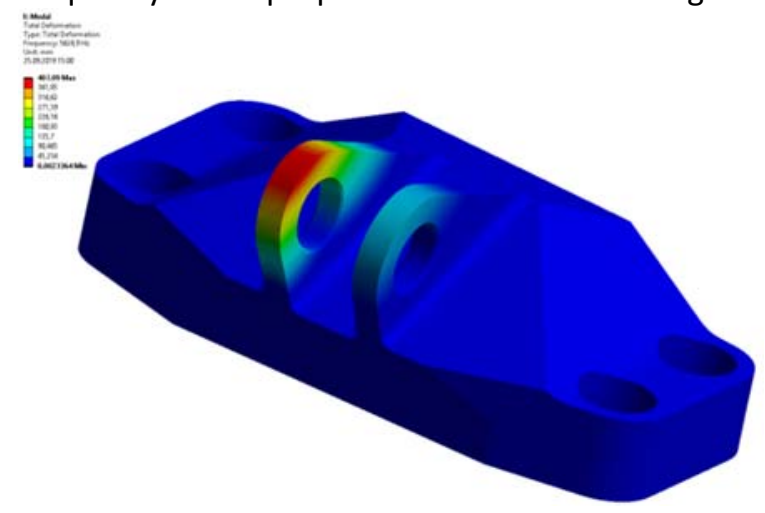

a)

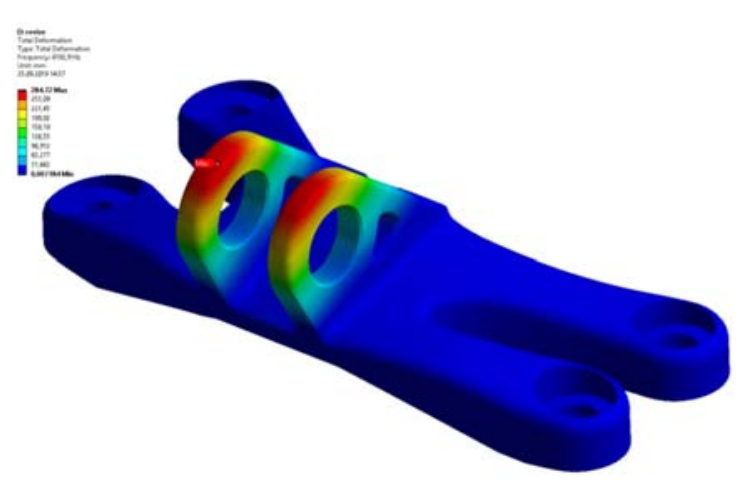

b)

Fig.4. Stress results of the (a) original model, (b) manufacturing model

As a shown as the Table 2, maximum equivalent stress is increased by rate of $5.19 \%$. According to this result, an acceptable increase is obtained. Also, the total mass is decreased by rate of $76.7 \%$. The mass reduction is previously presented as rate of $80 \%$, however total mass reduction is figured out only about $3.3 \%$ less than this target. Moreover, the first natural frequency of the structure decreased from $5625 \mathrm{~Hz}$ to $4183 \mathrm{~Hz}$. Essentially, this is undesirable for the vibrational cases. However, in a 76 percent mass reduction, it is not important that this value decrease at this rate.

Table 2. Compared results

\begin{tabular}{|l|c|c|}
\hline & $\begin{array}{c}\text { Original } \\
\text { Model }\end{array}$ & $\begin{array}{c}\text { Optimized } \\
\text { Model }\end{array}$ \\
\hline $\begin{array}{l}\text { Maximum Equivalent } \\
\text { Stress [MPa] }\end{array}$ & 128,21 & 135,55 \\
\hline Mass [Kg] & 2,0517 & 0,4780 \\
\hline $\begin{array}{l}\mathbf{1}^{\text {st }} \text { Natural Frequency } \\
\text { [Hz] }\end{array}$ & 5625 & 4183 \\
\hline
\end{tabular}




\section{CONCLUSION}

This paper presents topology optimization of the jet engine bracket using finite element analysis (FEA) of a challenge that was proposed from GE Aviation. Topology optimization is conducted according to the three objective functions. The manufacturing model is obtained and compared with the original model according to the maximum equivalent stress, mass reduction and natural frequency. According to the results, lighter body can also be used to obtain the same strength and approximate frequency results. As a result of the paper, ANSYS is a successful and effective method for topology optimization in mass reduction problems.

\section{REFERENCES}

[1] S. Kirthana, M. K. Nizamuddin, Finite Element Analysis and Topology Optimization of Engine Mounting Bracket. Materials Today: Proceedings, 5 (9), 2018: 19277-19283.

https://doi.org/10.1016/i.matpr.2018.06.286

[2] D. Gunwant, A. Misra, Topology Optimization of sheet metal brackets using ANSYS. MIT International Journal of Mechanical Engineering, 2 (2), 2012: 120-126.

[3] P. Wu, Q. Ma, Y. Luo, C. Tao, Topology optimization design of automotive engine bracket. Energy and Power Engineering, 8 (4), 2016: 230-235.

https://doi.org/10.4236/epe.2016.84021

[4] U. S. Ghorpade, D. Chavan, V. Patil, M. Gaikwad, Finite Element Analysis and Natural Frequency Optimization of Engine Bracket. International Journal of Mechanical and
Industrial Engineering (IJMIE), 2 (3), 2012: 2012: 1-6.

[5] S. Naghate, S. Patil, Modal Analysis of Engine Mounting Bracket Using FEA. International Journal of Engineering Research and Applications (IJERA), 2 (4), 2012: 1973-1979.

[6] J. W. Chang, Y. S. Lee, Topology optimization of compressor bracket. Journal of mechanical science and technology, 22 (9), 2008: 16681676.

https://doi.org/10.1007/s12206-008-0428-3

[7] J. S. Dhillon, P. Rao, V. Sawant, Design of engine mount bracket for a FSAE car using finite element analysis. Journal of Engineering Research and Applications, 4 (9), 2014: 74-81.

[8] H. S. Chang, A study on the analysis method for optimizing mounting brackets. SAE International. Technical Paper 2006-01-1480, 2006.

https://doi.org/10.4271/2006-01-1480

[9] Internet source: GE jet engine bracket challenge:

https://grabcad.com/challenges/ge-jet-engine-bracketchallenge

[10] M. Peters, J. Kumpfert, C. H. Ward, C. Leyens, Titanium alloys for aerospace applications. Advanced engineering materials, 5 (6), 2003: 419-427.

https://doi.org/10.1002/adem.200310095

[11] V. Matariya, H. Patel, Topological Optimization of Automobile Rotor Disk Brake. SSRG International Journal of Mechanical Engineering, 6 (4), 2019: 2327.

https://doi.org/10.14445/23488360/IJME$\underline{\text { v614P105 }}$ 